\title{
COISA JULGADA E CUMPRIMENTO DAS DECISÕES PARCIAIS DE MÉRITO: EFETIVA DIMINUIÇÃO DO TEMPO DO PROCESSO?
}

\author{
José Henrique Mouta Araújo*
}

\section{RESUMO}

Tema que desafia os estudiosos do direito está ligado ao tempo de duração dos processos e a grande quantidade de incidentes processuais. O CPC provoca grande reflexão acerca da necessidade de se pensar o processo como meio de garantia de direitos, com a efetiva da brevidade da prestação jurisdicional, evitando-se a eternização da discussão envolvendo capítulos de mérito resolvidos precocemente. Este trabalho pretende enfrentar a duração razoável do processo, com a necessária revisão de aspectos ligados à formação de coisa julgada, a recorribilidade das decisões judiciais e os seus reflexos em relação às normas fundamentais do direito processual.

Palavras-chave: Duração razoável do processo, novo CPC, coisa julgada, tempo do processo, recurso.

\section{RES JUDICATA AND COMPLIANCE WITH PARTIAL DECISIONS OF MERIT: EFFECTIVE DECREASE OF TIME OF PROCEDURE?}

\begin{abstract}
Theme that challenges the scholars of law is linked to the length of the proceedings and the large number of procedural incidents. The CPC provokes great reflection on the need to think of the process as a means of guaranteeing rights, with the effective brevity of the jurisdictional provision, avoiding the eternalization of the discussion involving chapters of merit solved early. This work intends to face the reasonable length of the process, with the necessary revision of aspects related to the formation of res judicata, the resorting of judicial decisions and their reflexes in relation to the fundamental rules of procedural law.
\end{abstract}

Key-words: Reasonable duration of the process, the new CPC, res judicata, process time, resource

\section{I- Introducão}

A grande indagação que se pretende analisar neste texto é se o fenômeno das decisões parciais e coisa julgada progressiva realmente alcança a duração razoável do processo, inclusive superando a crise numérica que assola o Poder Judiciário Nacional.

\footnotetext{
* Mestre (UFPA), Doutor (UFPA) e Pós-doutor (Universidade de Lisboa), professor do IDP/DF, CESUPA/PA e da FAMETRO/AM, procurador do Estado do Pará e advogado. www.henriquemouta.com.br
} 
Necessário, para tanto, partir de uma premissa: o tempo demasiado do processo e a crise numérica são fatores que desestimulam a procura pelo Poder Judiciário.

A preocupação do Código é tanta que, no diálogo com a Constituição que é travado logo no capítulo inicial voltado para as normas fundamentais do processo civil, o legislador consagra o direito a uma decisão de mérito justa e efetiva ( $\operatorname{art} .6^{\circ}$ ).

Visando a correta compreensão dos objetivos do legislador no que tange ao fenômeno da coisa julgada, o intérprete deve recordar as normas fundamentais que se relacionam diretamente com este tema: cooperação (art. $6^{\circ}$, do CPC), primazia de mérito (art. $4^{\circ}$, do CPC) e própria duração razoável do processo (art. $6^{\circ}$, do CPC). Sobre, vale citar passagem de Alexandre Câmara (2015, p. 6): “consolida-se, aí, um princípio fundamental: o de que se deve dar primazia à resolução de mérito (e à produção do resultado satisfativo do direito) sobre o reconhecimento de nulidades ou de outros obstáculos à produção do resultado normal do processo civil. Eis, aí, portanto, o princípio da primazia da resolução de mérito".

Destarte, a imunização mais rápida de uma decisão judicial, permitindo seu imediato e definitivo cumprimento, serve como um fator positivo em busca da brevidade da prestação jurisdicional.

É sabido que a duração excessiva dos litígios no Brasil não é um fato isolado. Ela está ligada a pouca quantidade de juízes, ao aumento progressivo de demandas reprimidas, o crescente número de "litigantes habituais", além da existência de instrumentos processuais dispensáveis.

Aliás, sobre os chamados litigantes habituais, vale a pena transcrever as lições de Mauro Cappelletti e Bryant Garth (1988, p. 25-6): “O professor Galanter desenvolveu uma distinção entre o que ele chama de litigantes "eventuais" e "habituais", baseado na freqüência de encontros com o sistema judicial. Ele sugeriu que esta distinção corresponde, em larga escala, à que se verifica com o sistema judicial e entidades desenvolvidas, com experiência judicial mais extensa. As vantagens dos habituais, de acordo com Galanter, são numerosas: 1) maior experiência com o Direito possibilitalhes maior planejamento do litígio; 2) o litigante habitual tem economia de escala, porque tem mais casos; 3) o litigante habitual tem oportunidades de desenvolver relações informais com os membros da instância decisora; 4) ele pode diluir os riscos da demanda com maior número de casos; 5) pode testar estratégias com determinados 


\section{COISA JULGADA E CUMPRIMENTO DAS DECISÕES PARCIAIS DE MÉRITO: EFETIVA DIMINUIÇÃO DO TEMPO DO PROCESSO?}

casos, de modo a garantir expectativa mais favorável em relação aos casos futuros. Parece que, em função dessas vantagens, os litigantes organizacionais são, sem dúvida, mais eficientes que os indivíduos".

Além de todas essas características devem ser somadas mais três, que deixam os litigantes habituais em posição diferenciada: a) a possibilidade de fazer uso de estratégias por vezes protelatórias, visando criar obstáculos à efetiva e célere prestação jurisdicional; b) a de ter menor prejuízo em face da duração da litispendência, em virtude de sua auto-suficiência; c) e a de provocar maiores incidentes processuais.

Há, nesse aspecto, claro desequilíbrio, cabendo ao sistema processual, inclusive, nas reformas já ocorridas e nas que estão sendo implementadas, diminuir cada vez mais essa distância. Esta preocupação também é objeto de reflexo por Nalini (1994, p. 20).

Luiz Guilherme Marinoni (1994, p. 2) há muito tempo vem mostrando preocupação com o fenômeno da lentidão da tutela jurisdicional, o que não só muitas vezes interessa ao réu, como também pode colocar em risco o princípio da isonomia processual.

Com efeito, na prática forense, é fácil perceber que os repeat players estão numa posição diferenciada e são os que mais utilizam a esfera recursal, interpondo maior quantidade de apelos aos Tribunais Superiores - muitos dos quais infundados e com demora na solução definitiva.

A própria demora nos julgamento dos recursos paradigmas que são afetados pelo STJ e STF (art. 1037, II, do CPC) também corrobora para o problema em questão.

Segundo Mancuso (2011, pp. 120-121): "não é difícil compreender que o conflito, uma vez judicializado, passa a se desenvolver de modo desigual em face das partes, conforme se trate daquela que usualmente comparece aos órgãos judiciários, ou daquela que raramente os visita, na condição de autor, réu ou interveniente. Aí se configuram duas classes de litigantes, tanto pessoas físicas ou jurídicas: (a) os habituais (repeat players, na terminologia norte-americana), que trabalham em economia de escala em sua relação com a justiça estatal (têm departamento jurídico próprio), contratam advocacia de partido, ou mantém Procuradorias organizadas) e por si não são propriamente prejudicadas pelas mazelas e deficiências da justiça oficial (isso quando delas não tiram proveito, apostando no quanto pior melhor); (b) os eventuais (one shoters players, na nomenclatura norte-americana), que raramente comparecem ao serviço judiciário estatal, e, por isso mesmo, os ônus, encargos e riscos inerentes ao processo lhes pesa extraordinariamente". 
Percebe-se, outrossim, que as comissões de reforma da Constituição e a comissão de Juristas (aliado a todos os profissionais que colaboraram na elaboração da redação final) do novo CPC procuraram enfrentar os pontos de estrangulamento da tutela processual tradicional com o objetivo de alcançar um processo civil de resultados e de efetiva proteção dos direitos humanos. Em última análise: as modificações constitucionais e processuais objetivam a garantia de um concreto e real acesso à justiça.

É dever ressaltar, portanto, que o processo deve ser visto como instrumento de proteção dos direitos humanos, com a consciência de seu importante papel por todos aqueles que atuam no âmbito da prestação jurisdicional. Por conseguinte, é possível aduzir que o acesso à justiça deve ser visto como tema de direitos humanos (e também de direito fundamental), objetivando o alcance da satisfação do objeto contido no direito material, ${ }^{*}$ sem dilações processuais indevidas (o que se convencionou denominar de duração razoável do processo).

Também Luiz Rodrigues Wambier (2005, p. 39) se preocupa com o tema, ao ensinar que: "o direito ao acesso à Justiça (isto é, o direito à efetividade da jurisdição) é um direito fundamental instrumental, pois sua inefetividade pode comprometer a efetividade de todos os outros direitos fundamentais (evidentemente, sem que sejam efetivos os mecanismos de defesa dos direitos fundamentais materiais, sua efetividade pode estar comprometida)".

Aliás, antes mesmo de se indagar o que seria a duração razoável do processo (art. $6^{\circ}$, do $(P C)$ e a necessidade de revisitar o tema da coisa julgada, é dever ressaltar que se trata de conceito indeterminado e que deve ser aplicado a cada caso concreto, observando-se os prazos para a prática dos atos processuais. Gajardoni (2003, p. 59) observa que: "eventuais razões que levem a uma duração que exceda o prazo fixado previamente pelo legislador, com base no direito a ser protegido, deve se fundar em um interesse jurídico superior, que permita justificar o quebramento da previsão contida na norma processual, no qual se inclui a alegação de excesso de demanda".

Neste fulgor, utilizando as lições de Tucci (2001, p. 172), o direito ao processo com duração razoável (sem dilações indevidas) é um direito subjetivo constitucional assegurado a todos os membros da coletividade a tutela jurisdicional de um prazo 
razoável, inclusive com previsão expressa no texto constitucional brasileiro (art. $5^{\circ}$, LXXVI).

Referido dispositivo significou (ou mesmo ratificou) claro e importante instrumento de proteção dos direitos humanos em nível processual, tendo em vista que a efetividade da tutela jurisdicional caminha em conjunto com o fator tempo. Como bem observam Luiz Alexandre Cruz Ferreira e Maria Cristina Vidotte Blanco Tárrega (2005, p. 455), caso a legislação infraconstitucional estabeleça eventual demora indevida da prestação da tutela jurisdicional, é possível defender sua inconstitucionalidade em face do inciso LXXVIII, do art. $5^{\circ}$, da CF/88.

A questão a ser enfrentada, a partir deste momento, se refere ao fenômeno da coisa julgada e sua ligação com a duração razoável do processo. Algumas perguntas que merecem reflexão: o CPC/15 alterou o tratamento do fenômeno da imunização da decisão judicial? Há a possibilidade de formação progressiva da coisa julgada pelo novo CPC? As decisões no curso do processo formam a coisa julgada e permitem o fracionamento do sistema de cumprimento e do prazo para a rescisória? As modificações efetivamente alcançarão a duração razoável do processo?

Vamos aos argumentos.

\section{A duracão razoável do processo e o fenômeno da coisa julgada}

O CPC/15 tem por objetivo superar alguns pontos de estrangulamento do sistema anterior e abreviar o tempo de duração dos processos judiciais. Em relação às modificações, um dos pontos mais importantes refere-se ao fenômeno da coisa julgada.

A partir deste momento, serão analisadas as modificações e os pontos polêmicos referentes à coisa julgada e às decisões parciais e se efetivamente o CPC/15 alcança os conceitos de celeridade, efetividade e duração razoável, como prevê o texto constitucional e as próprias normas fundamentais processuais.

\section{$\underline{\text { II.1- A resolucão parcial e o cumprimento de sentenca em momentos diferenciados }}$}

O primeiro aspecto que provoca reflexão em relação à coisa julgada e a duração razoável do processo, diz respeito aos pronunciamentos parciais de mérito proferidos durante $\mathrm{o}$ andamento do feito. 
Destarte, a discussão ligada à resolução parcial de mérito (ARAUJO, 2007, pp. 30 e seguintes) ganhou maior espaço desde as reformas ocorridas ainda no CPC/73. Com o $\mathrm{CPC} / 15$, é razoável afirmar que ganhou espaço aspectos práticos ligados à formação da coisa julgada e os reflexos no sistema de cumprimento, nos recursos e, em última análise, na duração razoável do processo.

Vale afirmar, especialmente após as alterações ocorridas nos arts. 162, §1 ${ }^{\circ}, 267,269$ e 273, do CPC/73, que parte da doutrina e jurisprudência reconhecia a existência de sentenças parciais (decisões, no curso do processo, que, mesmo não encerrando a fase de conhecimento, poderiam ser enquadrar nos arts. 267 e 269 da legislação processual), ao passo que outra parte defendia a existência de decisões interlocutórias de mérito no curso da relação processual (ARAUJO, 2004, p. 207).

O tema é importante e reflete no $\mathrm{CPC} / 15$, tendo em vista a consagração da possibilidade de interposição de agravo de instrumento contra as decisões parciais de mérito (arts. 203, §2 $2^{\circ}$ c/c arts. 356 e 1015, II, do Código). Durante o andamento da relação jurídica processual, especialmente nos casos de cumulação simples de pedidos, há o amadurecimento precoce de um e a necessidade de continuidade do feito em relação ao outro.

Nestes casos, é dever indagar: é possível o desmembramento da resolução do mérito, em relação a um dos pedidos, inclusive mitigando o dogma da unicidade do julgamento? Essa decisão faz coisa julgada imediatamente permitindo seu cumprimento definitivo, abreviando o tempo do processo? É possível a entrega efetiva do bem jurídico discutido neste pedido resolvido antecipadamente?

Em situações práticas, portanto, é possível que um dos capítulos cumulados necessite de instrução probatória, enquanto o outro já esteja maduro em face da inexistência de fatos contraditórios ou mesmo quando o réu o reconhece juridicamente.

Realmente, pedido incontroverso é pedido reconhecido ou mesmo não impugnado, podendo ocorrer quando, havendo cumulação (em regra a cumulação simplessomatória sem dependência) de pedidos, o réu impugna apenas um deles (art. 356, I, do CPC).

Assim, considerando que a incontrovérsia foi gerada em decorrência de atitude do próprio réu, não parece razoável adiar esse fracionamento do julgamento e, consequência, a resolução imediata deste pedido incontroverso enquadrando-se nas 


\section{COISA JULGADA E CUMPRIMENTO DAS DECISÕES PARCIAIS DE MÉRITO: EFETIVA DIMINUIÇÃO DO TEMPO DO PROCESSO?}

disposições dos arts. 273, § 6 ${ }^{\circ}, 330$, II e 269, do CPC de 1973 e art. 356, I, do $\mathrm{CPC} / 15$.

J. J. Calmon de Passos (2004, p. 72), ao abordar o $§ 6^{\circ}$ do art. 273, do CPC de 1973, corretamente concluiu que não recorrida a decisão que assim o entendeu, transita em julgado. Já Marcelo Abelha Rodrigues (2003, p. 222) aponta, com um exemplo: “se João propõe duas demandas em face de José e este oferece contestação em apenas uma delas, certamente que se afastando da regra do art. 320, tudo leva a crer que será aplicado o art. 330, II, o CPC (julgamento antecipado da lide). Todavia, se João propõe uma só demanda com dois pedidos cumulados, por razões de economia processual, e José contesta apenas um deles, porque não se admitir um julgamento antecipado parcial, ou seja, daquilo que não foi impugnado? Ora, deixando as indagações de lado, a verdade é que pelo menos, a partir de agora, numa hipótese como esta última, poderá João ser beneficiado com a antecipação da tutela, caso a queira".

Ademais, a redação atribuída ao art. 162, do CPC de 1973 (pela Lei nº 11.232/05) para o conceito de sentença, e também o texto do art. 203, do CPC/15, demonstram que esta necessariamente não encerra o processo, uma vez que o feito poderá seguir para a fase de cumprimento. Ora, se a sentença não encerra - em regra - o procedimento, da mesma forma poderá ocorrer decisão interlocutória de conteúdo meritório capaz de ensejar o seu cumprimento provisório ou definitivo, mesmo com o prosseguimento da relação processual.

Se for observado o julgamento antecipado do mérito, é possível concluir a hipótese do art. 356, I, do CPC/15 (e também do art. 354, parágrafo único, do CPC/15) trata de antecipação parcial do próprio objeto litigioso, ensejando a formação da coisa julgada e abreviando o início do cumprimento da decisão (não seria cumprimento de sentença). Como aduz Fredie Didier de Souza Jr., em obra elaborada em coautoria (2003, p. 72): "não é antecipação dos efeitos da tutela, mas emissão da própria solução judicial definitiva, fundada em cognição exauriente e apta, inclusive, a ficar imune com a coisa julgada material. E, por ser definitiva, desgarra-se da parte da demanda que resta a ser julgada, tornando-se decisão absolutamente autônoma: o magistrado não precisa confirmá-la em decisão futura, que somente poderá examinar o que ainda não tiver sido apreciado". 
Ainda sobre o assunto, defende Flávio Luiz Yarshell (2005, p. 197): "situação diversa ocorre se a antecipação da tutela se dá porque parte da demanda é incontroversa, conforme dicção do $\$ 6^{\circ}$ do art. 273 do CPC. É que, nesse caso, conforme anteriormente acenado, parece lícito afirmar que não há mais o caráter de 'provisório' no ato; tanto que a doutrina tem afirmado que, nessa hipótese, não vigora o limite do 'perigo de irreversibilidade’ de que fala o $\$ 2^{\circ}$ do art. 273 da lei processual”. E conclui: “e, sendo assim, não há como negar que, mesmo veiculado por decisão interlocutória, há julgamento do mérito, a ensejar desconstituição por ação rescisória".

A propósito, o próprio Agravo de Instrumento contra esta decisão parcial deve ter o mesmo procedimento da apelação (art. 512, do CPC), tendo em vista que ambos são recursos cabíveis contra o pronunciamento que aprecia o objeto litigioso, com a apresentação de defesa oral e, se for o caso, a aplicação da técnica de ampliação do julgamento (art. 942, § $3^{\circ}$, II, do CPC).

Neste sentido, aponta Pedro Miranda de Oliveira (2017, p. 203): “o regime do agravo de instrumento interposto contra decisão parcial (com ou sem mérito) deve ser o mesmo do recurso de apelação. A única exceção é o órgão perante o qual o recurso deve ser interposto: a apelação no juiz de primeiro grau; o agravo de instrumento no respectivo tribunal. E só!”.

Esse desmembramento do julgamento de mérito e a recorribilidade permite o deslocamento de institutos "típicos" da apelação, para este agravo de instrumento previsto no art. 356, do CPC, a saber: interposição adesiva, efeito suspensivo legal e automático, aplicação da teoria da causa madura (art. 1013, §3º, do CPC), sustentação oral, remessa necessária (CUNHA, 2016, p. 1324-1325) e de utilização da técnica de ampliação do julgamento (art. 942, §3º II, do CPC).

De outro prisma, se o sistema processual permite, e até estimula, a cumulação de pedidos, o amadurecimento precoce de um deles enseja o desmembramento da tutela definitiva. Esta afirmação serve para se concluir que a sentença, por vezes, é o pronunciamento que encerra no máximo procedimento em $1^{\circ}$ grau (isso sem falar no cumprimento do julgado); contudo, nos casos de pedidos cumulados, sendo um deles apreciado precocemente - rejeitado ou acatado - tal decisão não se configura sentença, mas sim decisão interlocutória definitiva, sujeitando-se a interposição de agravo de instrumento (art. 1015, II, do CPC/15). 
O sistema processual, portanto, estimula o desmembramento do objeto litigioso do processo e a entrega imediata do capítulo amadurecido precocemente. Rodrigo Ramina de Lucca aponta que não se trata de juízo arbitrário do magistrado, mas de uma constatação racional de que não há necessidade de dilação probatória (2016, p. 138).

Aliás, os pontos ora apresentados trazem importantes consequências, uma vez que a coisa julgada não ocorrerá apenas em um só momento (CARNELUTTI, 1958, p. 272) o que reflete na fluência do prazo decadencial para o ajuizamento da ação rescisória e mesmo na possibilidade de execução definitiva (cumprimento da decisão interlocutória) em momentos diferenciados.

No tema, Daniel Mitidiero (2005, p. 555) aponta, indicando dispositivos do CPC/73, que "o reconhecimento a que alude o Código no art. 269, II, é o reconhecimento total. O reconhecimento parcial não dá ensejo à extinção do processo, embora possa dar lugar à cisão da decisão de mérito da causa, por obra do art. 273, § 6 $6^{\circ}$, do CPC”.

Destarte, com a literalidade do permissivo constante no CPC e sem maiores questionamentos, o sistema processual consagra a formação progressiva da coisa julgada e a possibilidade de execução definitiva em momentos diferentes estimulando, de um lado, a entrega do mérito de forma progressiva e, de outro, permitindo a efetivação da prestação jurisdicional em vários momentos no mesmo procedimento.

Este fracionamento do julgamento do mérito tende a estimular a brevidade da tutela jurisdicional, como no caso enfrentado no Enunciado 513 do Fórum Permanentes de Processualistas Civis: “(art. 356; Lei 8.245/1991) Postulado o despejo em cumulação com outro(s) pedido(s), e estando presentes os requisitos exigidos pelo art. 356, o juiz deve julgar parcialmente o mérito de forma antecipada, para determinar a desocupação do imóvel locado".

Em última análise, há claro prestígio à possibilidade de execução definitiva de um capítulo de mérito, ainda estando outros do mesmo decisum pendentes de apreciação recursal, como forma de alcançar a imediata tutela do direito e, em síntese, evitando dilações indevidas.

No mesmo sentido, observa Nery Júnior (2004, p. 454) que: “entendemos ser possível a execução definitiva da parte da sentença já transitada em julgado, em se tratando de recurso parcial, desde que observadas certas condições: a) cindibilidade dos capítulos da decisão; b) autonomia entre a parte da decisão que se pretende executar e a parte objeto 
de impugnação; c) existência de litisconsórcio não unitário ou diversidade de interesses entre os litisconsortes, quando se tratar de recurso interposto por apenas um deles".

Tudo isso demonstra que, nas situações envolvendo resolução parcial de mérito, estarse-á diante de claro instrumento de prestígio à celeridade e duração razoável do processo, com o fracionamento do momento do cumprimento do julgado e a permissão de imediata satisfação do bem jurídico objeto da referida tutela jurisdicional.

\section{II.2- Recorribilidade parcial e coisa julgada em momentos diferenciados: tentativa de alcance da brevidade da prestacão jurisdicional}

Como se demonstrou até o momento, na formação do título executivo, a natureza do provimento é menos importante do que a consequência processual por ele gerada, razão pela qual pouco importa se se trata de sentença propriamente dita ou resolução parcial de mérito: existindo conteúdo meritório e cognição suficiente para provocar execução definitiva mesmo que em autos autônomos, é possível seu cumprimento definitivo e a formação de coisa julgada parcial.

Mais uma vez não se pode afirmar que a possibilidade de execução definitiva de um capítulo antes do efetivo trânsito em julgado dos demais viola princípios constitucionais, considerando a autonomia dos pedidos cumulados. Pelo contrário, alcança a duração razoável e evita prolongamento desnecessário da litispendência.

Aliás, houve a formação prematura de título executivo parcial em decorrência de conduta da parte, que deixou de interpor agravo de instrumento contra a resolução parcial de mérito ou apresentou recurso parcial diante de uma sentença em capítulos. Isto pode ocorrer também em caso de sucumbência recíproca em que não há a interposição de recurso principal ou mesmo adesivo.

Os capítulos não impugnados de uma decisão podem, desde já e dependendo do caso concreto, ensejar execução definitiva, mesmo inexistindo efetivamente o trânsito em julgado total do decisum.

Este raciocínio ligado ao conceito de resolução parcial de mérito também reflete no prazo para ajuizamento de ação rescisória. O CPC/15 provoca novas indagações ligadas à forma da contagem do prazo decadencial nos casos de decisões parciais de mérito.

Nelson Nery Júnior (2004, p. 130) faz indagação semelhante, partindo em seguida para a correta resposta: "seria, entretanto, rescindível essa decisão interlocutória de mérito? 
A resposta afirmativa se impõe. Conforme já dissemos, para o cabimento da ação rescisória é relevante a matéria decidida. É consequiência lógica da admissão da possibilidade de questão de mérito vir a ser resolvida por decisão interlocutória o fato de que, precisamente por ser de mérito, seja passível de ataque pela via da ação rescisória”. Realmente, é necessário rever alguns conceitos tidos como intangíveis no sistema. A coisa julgada não ocorre apenas e tão-somente na sentença de mérito, mas sempre que existir decisão de mérito com cognição suficiente para a imunização.

A segurança jurídica prestigia claro sistema de imutabilidade à decisão de mérito no momento em que não houver interposição de recurso impugnando o capítulo específico. Este raciocínio também está de acordo com a necessidade de alcance do devido processo legal e a tempestividade da prestação jurisdicional.

Óbvio que, na prática forense, poderá até ocorrer certa incongruência entre julgados oriundos da mesma relação processual e imunizados em momentos diferentes. Contudo, tal aspecto não pode ser levado em consideração para se desconsiderar a possibilidade do fenômeno da coisa julgada parcial e progressiva. Como bem observa Leonardo José Carneiro da Cunha (2005, pp. 219-220): "se o recurso for parcial, a análise do tribunal restringe-se a essa parte, não devendo incursionar na outra parte, não atacada pelo recurso.(...) Ora, se é certo que a sentença pode ser impugnada no todo ou em parte (CPC, art. 515), é curial que a parte não atacada terá transitado em julgado, operando-se a coisa julgada material. Desse modo, caso o tribunal desfaça toda a sentença, tendo o recurso sido parcial, exsurgirá ofensa à coisa julgada".

A dificuldade não pode ser desconsiderada. O correto não é a expedição apenas de uma certidão de trânsito em julgado quando, por exemplo, pretende o interessado ajuizar ação rescisória, mas várias certidões dependendo de quantos capítulos forem imutabilizados no decorrer da relação processual.

A questão passa pela interpretação do efeito substitutivo do recurso previsto no art. 1008, do CPC/15. A expressão "no que tiver sido objeto de recurso" indica que, em caso de recurso parcial, a devolutividade do apelo e a substitutividade do acórdão também serão parciais.

A jurisprudência pátria, formada ainda com base no CPC/73, se comporta de forma divergente no que respeita à formação progressiva da coisa julgada nos casos envolvendo recurso parcial. Inicialmente, o STJ tinha decisões favoráveis à formação progressiva da imunização máxima (REsp. 201.668-PR, 5 T., Rel. Min. Edson Vidigal, 
unânime, DJ de 28.06.1999, p. 143; REsp 212.286-RS, 6 T, Rel. Min. Hamilton Carvalhido, unânime, DJ de 29.10.2001, p. 276; REsp 278614/RS, 5 T, Rel. Min. Ministro JORGE Scartezzini - J. de 04/09/2001 - DJ de 08.10.2001 p. 240).

Contudo, em outros julgados (AR 846, EDAR 1.275, ERESP 404.777) e no Enunciado 401 da Súmula de sua Jurisprudência dominante, o STJ consagra que o prazo para a ação rescisória conta-se a partir do trânsito em julgado da última decisão.

O STF, no julgamento do RE 666589/DF (rel. Min Marco Aurélio - DJ de 02.06.2014) entendeu que o prazo decadencial da ação rescisória, nos casos da existência de capítulos autônomos, deve ser contado do trânsito em julgado de cada decisão. Esta é a ementa do julgado: "Coisa julgada - Envergadura. A coisa julgada possui envergadura constitucional. Coisa julgada - Pronunciamento judicial - Capítulos autônomos. Os capítulos autônomos do pronunciamento judicial precluem no que não atacados por meio de recurso, surgindo, ante o fenômeno, o termo inicial do biênio decadencial para a propositura da rescisória”.

É fácil perceber, portanto, que o tema (momento da coisa julgada) é polêmico e está sendo enfrentado diretamente no $\mathrm{CPC} / 15$, com a razoável interpretação de que, nestas duas situações (decisões parciais e recursos com impugnação parcial) há imutabilidade parcial da decisão de mérito impugnada parcialmente.

Esta observação provoca, ao interessado em promover a ação rescisória: a) a necessidade de se demonstrar, mediante certidão, o trânsito em julgado da resolução (quaisquer das três - sentença, interlocutória ou mesmo acórdão) de mérito; b) a possibilidade de conciliar o instituto do cumprimento definitivo de um pedido apreciado prematuramente com outro sequer transitado em julgado; c) possibilidade de coexistir a execução (cumprimento) provisória e definitiva na mesma relação jurídica processual, etc.

Logo, é necessária a revisitação do tema (momento da coisa julgada e duração razoável do processo), incluindo o posicionamento de alguns julgados que consagram a coisa julgada apenas após o julgamento do último recurso. A rigor, aliás, merecem ser revisitados conceitos tradicionais como o de coisa julgada, rescisória, trânsito em julgado, decisão de mérito, prazo decadencial para desconstituição do decisum e, em última análise, do próprio reflexo em relação à duração razoável do processo. 
Com o objetivo de alcançar os fins delimitados no capítulo que trata das normas fundamentais do direito processual, é mister defender que o prazo da demanda desconstitutiva encerra-se em dois anos da última decisão do processo, mas nada impede que, em caso de julgamento antecipado parcial (art. 356, do CPC) ou mesmo de recurso parcial, o interessado utilize de imediato da rescisória, até com o objetivo de obter tutela provisória com o fito de suspender o cumprimento deste capítulo decisório (art. 969, do CPC).

Contudo, Délio Mota de Oliveira Júnior (2015, p. 121) entende o prazo de dois anos é contado "do respectivo trânsito em julgado da última decisão proferida em relação a cada capítulo autônomo e independente". Já Ravi Peixoto (2015, p. 166) afirma que o prazo se referente a última decisão de cada capítulo; ou seja, a "decisão que substitui por último cada capítulo".

Por seu turno, Welder Queiróz dos Santos (2017, p. 341) entende que "a expressão "última decisão proferida no processo" deve ser interpretada como a última decisão sobre o pedido julgado por decisão parcial de mérito ou, em caso de recurso parcial, do trânsito em julgado do capítulo não impugnado".

A rigor, enquanto não houver definição jurisprudencial acerca do prazo para a rescisória, a sociedade suportará o risco da instabilidade dos nossos tribunais. Quem sabe o STJ poderá avocar o tema em Recurso Especial repetitivo, a fim de concluir pela melhor interpretação do art. 975, do CPC, como fez neste ano de 2018 em relação ao rol das interlocutórias agraváveis (REsp 1.704.520 - Rel. Min. Nancy Andrighi).

De qualquer maneira, todos os institutos ligados à decisão parcial de mérito aspectos procuram abreviar a prestação jurisdicional, com a diminuição do tempo do processo em relação aos capítulos que foram objeto de recurso parcial e, em última análise, antecipar o início da fase de cumprimento de sentença e a outorga da prestação jurisdicional àquele que tem razão.

\section{III- Conclusões}

- O tempo demasiado do processo é um fator que desestimula a procura pelo Poder Judiciário.

- A imunização mais rápida de uma decisão judicial, permitindo seu imediato e definitivo cumprimento, serve como um fator positivo em busca da brevidade da prestação jurisdicional. 
- As comissões de reforma da Constituição e a comissão de Juristas (aliado a todos os profissionais que colaboraram na elaboração da redação final) do CPC/15 procuraram enfrentar os pontos de estrangulamento da tutela processual tradicional com o objetivo de alcançar um processo civil de resultados e de efetiva proteção dos direitos humanos. Em última análise: as modificações constitucionais e processuais objetivam a garantia de um concreto e real acesso à justiça.

- O direito ao processo com duração razoável (sem dilações indevidas) é um direito subjetivo constitucional assegurado a todos os membros da coletividade a tutela jurisdicional de um prazo razoável, inclusive com previsão expressa no texto constitucional brasileiro (art. $5^{\circ}$, LXXVI).

- O CPC/15 pretende superar alguns pontos de estrangulamento do sistema anterior e abreviar o tempo de duração dos processos judiciais. Em relação às modificações, um dos pontos mais importantes refere-se ao fenômeno da coisa julgada.

- Considerando que o sistema processual permite, e até estimula, a cumulação de pedidos, o amadurecimento precoce de um deles enseja o desmembramento da tutela definitiva.

- A sentença, por vezes, é o pronunciamento que encerra no máximo procedimento em

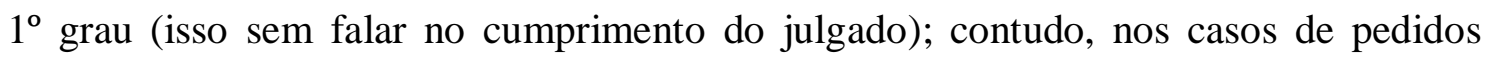
cumulados, sendo um deles apreciado precocemente - rejeitado ou acatado - tal decisão não se configura sentença, mas sim decisão interlocutória definitiva, sujeitando-se a interposição de agravo de instrumento (art. 1015, II, do CPC/15).

- Nas situações envolvendo resolução parcial de mérito, estar-se-á diante de claro instrumento de prestígio à celeridade e duração razoável do processo, com o fracionamento do momento do cumprimento do julgado e a permissão de imediata satisfação do bem jurídico objeto da referida tutela jurisdicional.

- Os capítulos não impugnados de uma sentença podem, desde já e dependendo do caso concreto, ensejar execução definitiva, mesmo inexistindo efetivamente o trânsito em julgado total do decisum.

- O CPC/15 provoca novas indagações ligadas à forma da contagem do prazo decadencial para a rescisória nos casos de decisões parciais de mérito.

- A segurança jurídica prestigia claro sistema de imutabilidade à decisão de mérito no momento em que não houver interposição de recurso impugnando o capítulo específico. 


\section{COISA JULGADA E CUMPRIMENTO DAS DECISÕES PARCIAIS DE MÉRITO: EFETIVA DIMINUIÇÃO DO TEMPO DO PROCESSO?}

Este raciocínio também está de acordo com a necessidade de alcance do devido processo legal e a tempestividade da prestação jurisdicional.

- Devem ser revisitados conceitos tradicionais como o de coisa julgada, rescisória, trânsito em julgado, decisão de mérito, prazo decadencial para desconstituição do decisum e, em última análise, do próprio reflexo em relação à duração razoável do processo.

- As decisões parciais de mérito consagram um processo voltado para a efetividade, brevidade e alcance do bem jurídico material tempestivamente.

\section{$\underline{\text { Referências }}$}

ARAÚJO, José Henrique Mouta. Coisa julgada progressiva \& resolução parcial de mérito. Curitiba, Juruá, 2007.

Tutela antecipada do pedido incontroverso: estamos preparados para a nova sistemática processual? Revista de Processo n. 116, São Paulo : Revista dos Tribunais, 2004

BAPTISTA DA SILVA, Ovídio. Curso de processo civil. 5. ed. São Paulo: Revista dos Tribunais, 2000. v. 1

CÂMARA, Alexandre Freitas. O princípio da primazia da resolução do mérito e o novo código de processo civil. Revista da Advocef, nov/2015.

CALMON DE PASSOS, José Joaquim. Comentários ao Código de Processo Civil. 9. ed. Rio de Janeiro: Forense, 2004

CAPPELlETTI Mauro \& GARTH, Bryant. Acesso à justiça. Trad. Ellen Gracie Northfleet. Porto Alegre: Sérgio Fabris, 1988

CARNELUTTI, Francesco. Diritto e processo. Napoli: Morano, 1958

CRUZ FERREIRA, Luiz Alexandre e TÁRREGA, Maria Cristina Vidotte Blanco. Reforma do poder judiciário e direitos humanos. In Reforma do judiciário. Teresa Arruda Alvim Wambier et al. (Org.). São Paulo: Revista dos Tribunais, 2005.

CUNHA, Leonardo Carneiro da. Da remessa necessária. In: ARRUDA ALVIM, Teresa et al. Breves comentários ao Código de Processo Civil. $2^{\mathrm{a}}$ edição, São Paulo : Revista dos Tribunais, 2016. 
Termo inicial do prazo para ajuizamento da ação rescisória, capítulos de sentença e recurso parcial (REsp 415.586-DF-STJ). Revista de Processo. n. 120. São Paulo: Revista dos Tribunais, 2005.

DIDIER JÚNIOR, Fredie; CHEIM JORGE, Flávio e RODRIGUES, Marcelo Abelha. A nova reforma processual. 2. ed. São Paulo: Saraiva, 2003

GAJARDONI, Fernando da Fonseca. Técnicas de aceleração do processo. São Paulo: Lemos \& Cruz, 2003

LUCCA, Rodrigo Ramina de. Julgamentos antecipados parciais de mérito. Revista de Processo 257, São Paulo: Revista dos Tribunais, 2016.

MANCUSO, Rodolfo de Camargo. Acesso à justiça: condicionantes legítimas e ilegítimas. São Paulo: Revista dos Tribunais, 2011

MARINONI, Luiz Guilherme. Efetividade do processo e tutela de urgência. Porto Alegre: Sérgio Fabris, 1994

. Tutela antecipatória e julgamento antecipado: parte incontroversa da demanda. 5. ed. São Paulo: Revista dos Tribunais, 2003.

MITIDIERO, Daniel Francisco. Comentários ao código de processo civil. São Paulo: Memória Jurídica, 2005

NALINI, José Renato. O juiz e o acesso à justiça. São Paulo: Revista dos Tribunais, 1994.

NERY JÚNIOR, Nelson. Teoria geral dos recursos. 6. ed. São Paulo: RT, 2004.

OLIVEIRA, Pedro Miranda de. O regime especial do agravo de instrumento contra decisão parcial (com ou sem resolução de mérito). Revista de Processo 264, São Paulo : Revista dos Tribunais, fev/2017.

OLIVEIRA JÚNIOR, Délio Mota de. A formação progressiva da coisa julgada material e o prazo para o ajuizamento da ação rescisória: a contradição do novo Còdigo de Processo Civil. Processo nos tribunais e meio de impugnação às decisões judiciais. Salvador : Juspodivm, 2005, v. 6 (Coleção novo CPC: doutrina selecionada, p. 121.

PEIXOTO, Ravi. Ação rescisória e capítulos de sentença: a análise de uma relação conturbada a partir do CPC/15. Processo nos tribunais e meios de impugnação às ordens judiciais. Salvador: Juspodivm, 2015, v 6(Coleção Novo CPC: doutrina slecionada, 166. 


\section{COISA JULGADA E CUMPRIMENTO DAS DECISÕES PARCIAIS DE MÉRITO: EFETIVA DIMINUIÇÃO DO TEMPO DO PROCESSO?}

RODRIGUES, Marcelo Abelha. Elementos de direito processual civil. 2. ed. São Paulo:

Revista dos Tribunais, 2003

SANTOS, Walder Queiróz dos. Ação rescisória contra decisão interlocutória de mérito e contra capítulo não recorrido". Revista de Processo 272, p. 327-347, São: Ed. Revista dos Tribunais, outubro/2017

TUCCI, José Rogério Cruz e. Garantia do processo sem dilações indevi das:

responsabilidade do Estado pela tempestividade da prestação jurisdicional. In Temas atuais de direito processual civil. César Augusto de Castro Fiúza, Maria de Fátima Freire de Sá e Ronaldo Bretãs C. Dias (Coord.). Belo Horizonte: Del Rey, 2001.

WAMBIER, Luiz Rodrigues. O contempt of court na recente experiência brasileira: anotações a respeito da necessidade premente de se garantir efetividade às decisões judiciais. Revista de Processo n. 119. jan. 2005. São Paulo: Revista dos Tribunais, 2005. YARSHELL, Flávio. Ação rescisória : juízos rescindente e rescisório. São Paulo : Malheiros, 2005. 